\title{
Key Technologies in Large-scale Rescue Robot Wrists
}

\author{
Zhidong Tang ${ }^{1}$ and Chao Yun ${ }^{2, a}$ \\ ${ }^{1}$ School of Mechanical Engineering and Automation, Beihang University, 100191 Beijing, China \\ ${ }^{2}$ Robot Institute, Beihang University, 100191 Beijing, China
}

\begin{abstract}
The full-Automatic Quick Hitch Coupling Device (full-AQHCD for short) is used as the starting point, key technologies in a large-scale rescue robot wrist, which is constituted by integrating a quick hitch coupling device, a turning device, and a swaying device together, are reviewed respectively. Firstly, the semi-AQHCD made domestically for the main-Arm Claw Wrist (main-ACW for short) is introduced, and the full-AQHCD imported from Oil Quick company in Sweden for the vice-Arm Cutter Wrist (vice-ACW for short) is presented. Secondly, aiming at three key technologies in the full-AQHCD including rotary joint technology, automatic docking technology and precise docking technology for quick action coupling, are concisely expressed. Thirdly, the hydraulic motor driving gear type slewing bearing technology of the turning device made domestically for the main-ACW is introduced, and the hydraulic motor driving worm type slewing bearing technology of the turning device imported from HKS company in Germany for the vice-ACW is presented, especially, the existing gap in the similar domestic technology is discussed. Subsequently, the hydraulic cylinder driving 4-bar linkage technology of the swaying device made domestically for the main-ACW is introduced, and the hydraulic double spiral swing cylinder technology of the swaying device imported from HKS company in Germany for the vice-ACW is presented, especially, the existing gap in the similar domestic technology is discussed. Finally, it is emphasized that these technological gaps have seriously restricted the ability of the vice-ACW to successfully work in future actual rescue combats, therefore, it must be highly valued in the follow-up research and development (R\&D) through cooperating with professional manufacturers in China, thereby making technological advances.
\end{abstract}

\section{Introduction}

By comparison with the no-automatic quick hitch coupling device, the semi-Automatic Quick Hitch Coupling Device (semi-AQHCD for short) has been popularized and applied widely so far. The concept of full-Automatic Quick Hitch Coupling Device (full-AQHCD for short) is introduced for the first time into "Double Powers, Intelligent, and Double Arms Series of Large-Scale Rescue Robot (DPIDASLSRR for short)", which is the national "12th 5-Year" science and technology support project. Due to the full-AQHCD belongs to the new things without precedent in China, for shortening the development cycle and reaching the international advanced level, among 20 ton, 40 ton and 60 ton (20 t, $40 \mathrm{t}$ and $60 \mathrm{t}$ for short, respectively) three series of prototype for "DPIDASLSRR", the $20 \mathrm{t}$ prototype imported a full-AQHCD product OQ65-3[1] from Oil Quick company in Sweden and 2

\footnotetext{
a Corresponding author : cyun18@vip.sina.com
} 
Degrees of Freedom (DOF/DOFs for short) of turning and swaying product TR-K180[2-3] from HKS company in Germany for the vice-Arm Cutter Wrist (vice-ACW for short) which mainly undertakes a dexterous mission with the help of the main-Arm Claw Wrist (main-ACW for short) which mainly undertakes a strength mission, this sort of three-in-one wrist is constituted by integrating a Quick Hitch Coupling Device (QHCD for short), a turning device, and a swaying device together. The $20 \mathrm{t}$ prototype subsequently participated in an actual rescue combat[4] of 7 magnitude earthquake in Ya'an of Sichuan province in April 20, 2013. The evaluation of the actual rescue combat has verified that the OQ65-3 and the TR-K180 have excellent quality, reliable performance and are suitable for China's natural conditions, therefore, realizing localization of them for $40 \mathrm{t}$ and $60 \mathrm{t}$ prototypes should be most desirable.

\section{Key technologies in large-scale rescue robot wrists}

\subsection{Wrist assemblies}

Figure 1 shows the wrist 1 of main arm 1 claw and the wrist 2 of vice arm 2 cutter of the 20 t prototype. Wrists of $40 \mathrm{t}$ and $60 \mathrm{t}$ prototypes are respectively corresponding to and similar to the ones of the $20 \mathrm{t}$ prototype. Claw and cutter are collectively referred to as attachments. Figure 2 shows the $20 \mathrm{t}$ prototype participating in the actual rescue combat of 7 magnitude earthquake in Ya'an of Sichuan province in April 20, 2013.

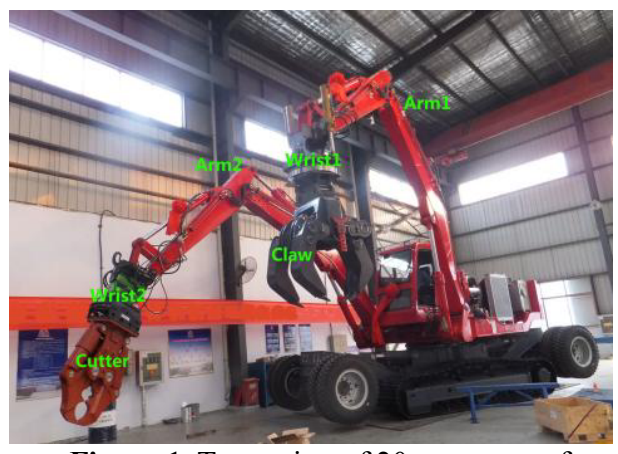

Figure 1. Two wrists of $20 \mathrm{t}$ prototype for large-scale rescue robot

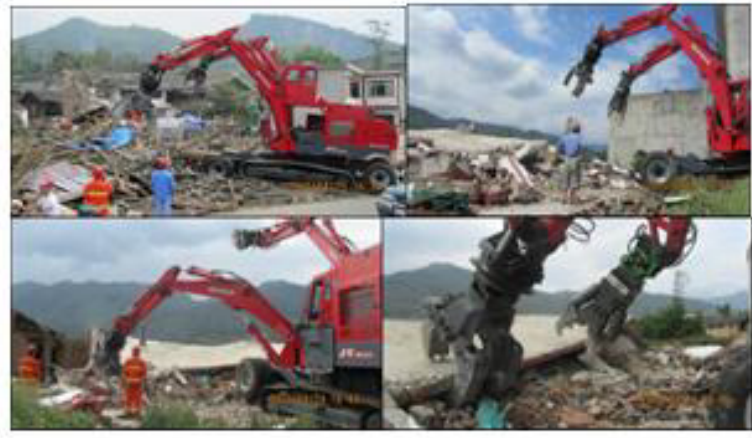

Figure 2. $20 \mathrm{t}$ prototype in actual rescue combat of 7 magnitude earthquake in Ya'an in April 20, 2013

Set in the prototype development description book, the technical specifications of the main-ACW undertaking strength mission are shown in Table 1, the technical specifications of the vice-ACW undertaking dexterous mission are shown in Table 2, and $t h$ is the tonnage for prototype. The performance of the $20 \mathrm{t}$ prototype in actual rescue combat proved that the swing speed of the swaying device and the rotary speed of the turning device both in equivalent to $5 \mathrm{r} / \mathrm{min}$ are appropriate, if more than $5 \mathrm{r} / \mathrm{min}$ are too fast and not conducive to the posture adjustment for attachments, if less than 5

Table 1. Technical specifications of main-ACW for large-scale rescue robot

\begin{tabular}{cccccccc}
\hline th. & $d_{\mathrm{s} 1} /$ & $v_{\mathrm{s} 1} /$ & $m_{\mathrm{s} 1} /$ & $d_{\mathrm{t} 1} /$ & $v_{\mathrm{t} 1} /$ & $m_{\mathrm{t} 1} /$ & $l d_{1} /$ \\
$/ \mathrm{t}$ & $\circ$ & $\left({ }^{\circ} / \mathrm{s}\right)$ & $(\mathrm{t} \cdot \mathrm{m})$ & $\circ$ & $(\% / \mathrm{s})$ & $(\mathrm{N} \cdot \mathrm{m})$ & $\mathrm{t}$ \\
\hline 20 & \pm 45 & 20 & $\mathrm{Ni1}$ & 350 & 45 & $\mathrm{Ni1}$ & 4 \\
40 & \pm 45 & $20 \sim 30$ & 4.5 & 350 & 45 & 1063 & 10.2 \\
60 & \pm 45 & $20 \sim 30$ & 6 & 350 & 45 & $\mathrm{Ni1}$ & 14 \\
\hline
\end{tabular}


Table 2. Technical specifications of vice-ACW for large-scale rescue robot

\begin{tabular}{cccccccc}
$\begin{array}{c}t n \\
/ \mathrm{t}\end{array}$ & $\begin{array}{c}d_{\mathrm{s} 2} / \\
\circ\end{array}$ & $\begin{array}{c}v_{s 2} / \\
(\% / \mathrm{s})\end{array}$ & $\begin{array}{c}m_{\mathrm{s} 2} / \\
(\mathrm{t} \cdot \mathrm{m})\end{array}$ & $\begin{array}{c}d_{\mathrm{t} 2} / \\
\circ\end{array}$ & $\begin{array}{c}v_{\mathrm{t} 2} / \\
(\% / \mathrm{s})\end{array}$ & $\begin{array}{c}m_{\mathrm{t} 2} / \\
(\mathrm{N} \cdot \mathrm{m})\end{array}$ & $\begin{array}{c}l d_{2} / \\
\mathrm{t}\end{array}$ \\
\hline 20 & \pm 55 & 18.3 & 1.5 & 360 & 48 & 3500 & 4 \\
40 & \pm 55 & $20 \sim 30$ & 2.5 & 360 & $18 \sim 30$ & $\mathrm{Nil}$ & 5.8 \\
60 & \pm 55 & $20 \sim 30$ & 4 & 360 & $18 \sim 30$ & $\mathrm{Nil}$ & 6 \\
\hline
\end{tabular}

$\mathrm{r} / \mathrm{min}$ are too slow. In the actual rescue combat, that is to say that time is the life, if the operating movement is very slow, then it will mean that fewer people will be saved and more people will dead.

$d_{\mathrm{s} 1} / d_{\mathrm{s} 2}$ are the counter-clockwise(+) and clockwise(-) maximum swing angles of the swaying device for the main/vice-ACW, it can be seen that the maximum swing range for the main/vice-ACW is $90^{\circ} / 110^{\circ}$, a difference of $20^{\circ}$. $v_{\mathrm{s} 1} / v_{\mathrm{s} 2}$ is the swing speed of the swaying device for the main/vice-ACW, which can be seen that it is equivalent to the rotation speed of $3 \sim 5 \mathrm{r} / \mathrm{min} . m_{\mathrm{s} 1} / m_{\mathrm{s} 2}$ is the swing moment of the swaying device for the main/vice-ACW (Nil indicates that it is not specified in the overall design of the prototype, the following is the same). $d_{\mathrm{t} 1} / d_{\mathrm{t} 2}$ is the rotary angle of the turning device for the main/vice-ACW, the main arm's $350^{\circ}$ means that it cannot fully rotate, the vice arm's $360^{\circ}$ means that it can fully rotate. $m_{\mathrm{t} 1} / m_{\mathrm{t} 2}$ is the rotary moment of the turning device for the main/vice-ACW. $v_{\mathrm{t} 1} / v_{\mathrm{t} 2}$ is the rotary speed of the turning device for the main/vice-ACW, which can be seen that the main arm's is equivalent to the rotation speed of $7.5 \mathrm{r} / \mathrm{min}$. The vice arm's speed is equivalent to the rotation speed of $3 \sim 5 \mathrm{r} / \mathrm{min}$, which means that the operating movement is adjustable between a bit too slow and appropriate, 20 t prototype's speed can be a bit too fast up to $8 \mathrm{r} / \mathrm{min}$. $l d_{1} / l d_{2}$ is the maximum static load on the main/vice-ACW when it works alone in operation.

Figure 3 shows the wrist assembly of the main arm claw for the $40 \mathrm{t}$ prototype. Figure 4 shows the wrist assembly of the vice arm cutter for the $40 \mathrm{t}$ prototype. The upper coupling parts is used to link the bucket rod and the connection rod at the end of the main/vice arm, for achieving the longitudinal swaying freedom of the main/vice-ACW. The lower coupling parts is used to link with attachments. However, the main-ACW does not need the lower coupling parts, but directly links with attachments. The main/vice-ACW assembly for the $60 \mathrm{t}$ prototype is correspondingly similar to the ones for the $40 \mathrm{t}$ prototype.

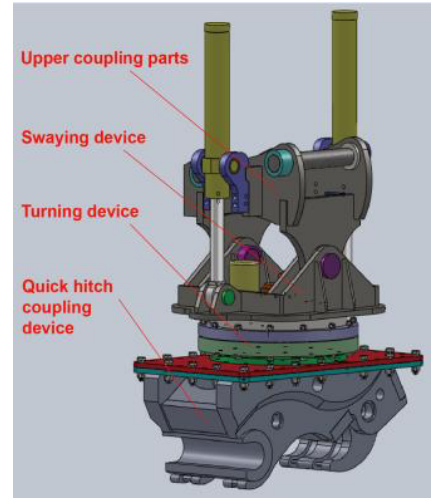

Figure 3. Wrist assembly of main arm claw of $40 \mathrm{t}$ prototype for large-scale rescue robot

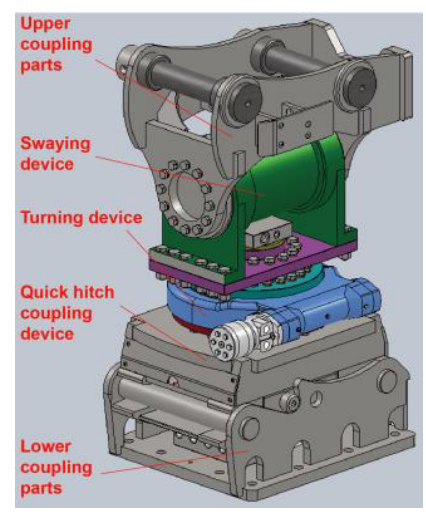

Figure 4. Wrist assembly of vice arm cutter of $40 \mathrm{t}$ prototype for large-scale rescue robot 


\subsubsection{Semi-AQHCD for main-ACW}

In 1996, the structure design added at the end of the mechanical arm of the construction machinery for conveniently hanging the attachments should be the early embryonic form of the QHCD[5]. Soon afterwards it began to popularize among excavators and loaders. The QHCD for loader at home and abroad is actually a kind of hydraulically controlled quick coupling bracket with four groups of hinge hole structure, through the hook to hang and the pin shaft to lock the attachments[6-7] as shown in Figure 5.a. Now this kind of quick coupling bracket with such structure has been widely used for loader in China. But because the quick coupling bracket is difficult to integrate 2 DOFs for both swaying and turning, so it is not suitable to be used as an integration platform for wrist.

Because the semi-AQHCD popular for excavator (as shown in Figure 5.b) has unsafe factors caused by the artificial participation still required in changing attachments, which has directly resulted some injuries in the UK, then the British introduced guidance documents for safe use of this kind of semi-AQHCD[8]. And, a death accident in Britain directly caused by this kind of semi-AQHCD made the British government pay attention to a non-mandatory ban again, namely new construction machinery shall not continue to be equipped with this kind of semi-AQHCD, those that have been equipped in the past may continue to be used for old construction machinery[9].

According to the trend of development, the semi-AQHCD for the main-ACW, which is shown in Figure 3 and Figure 5.b, will eventually fall into disuse because of occurrence of the full-AQHCD, but there will be a long period of time for its existence in China.

\subsubsection{Full-AQHCD for vice-ACW}

So far, at home and abroad the definition of full-AQHCD is just those that as long as have the function of automatic locking/unlocking attachments[10-12] as shown in Figure 6. In recent years the foreign improvements regarding this kind of full-AQHCD mainly include structure design for automatic security proof latch off[13-15], structure design for lubrication measures[16-17], design for anti-unlock at hydraulic failure time[18-19], structure design and hydraulic control measures for both ends with movable paws[20-22].

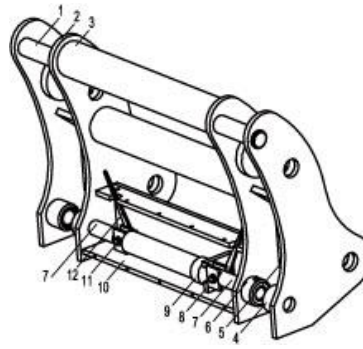

(a) for loader

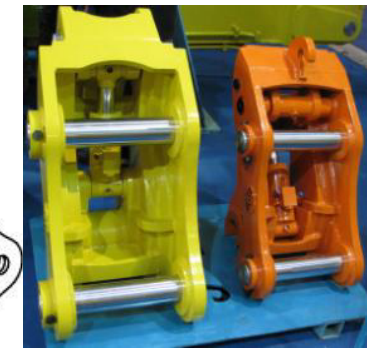

(b) for excavator

Figure 5. Quick hitch coupling device

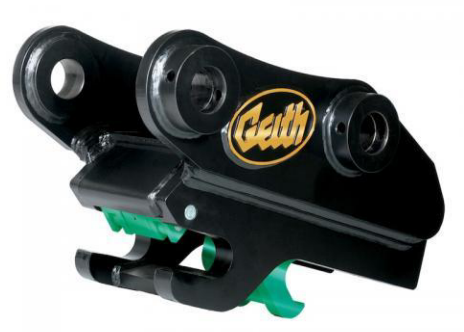

Figure 6. Automatic quick hitch coupling device

But the full-AQHCD described in this paper refers to not only the function of automatically locking/unlocking the attachments but also the function of automatically connecting/disconnecting the oil lines of the attachments. The open foreign literature on the automatically connecting/disconnecting the oil lines of the attachments is few, and is limited to this kind of directly automatic connection between the end of the mechanical arm of the construction machinery and the oil lines of the attachments[23-24], and does not involve the QHCD in it. Three key technologies involved in the full-AQHCD for the vice-ACW shown in Figure 4 are studied and listed as follows:

(1) Rotary joint technology as shown in Figure 7. A rotary joint transporting a liquid or gas from a stationary end to a moving side is a very wide range of key components. The study, analysis and comparison of the structural forms of the existing domestic and foreign rotary joints and central turning hydraulic joints are carried out. 


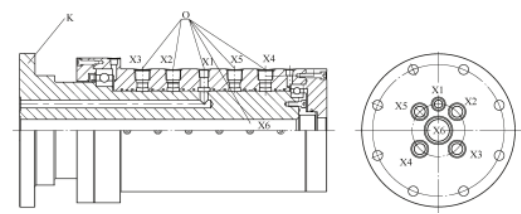

Figure 7. National standard Z6F type multi-channel cylindrical elastomer sealing rotary joint

(2) Automatic docking technology of quick action coupling. Aiming at the two quick action couplings, including ISO7241 (as shown in Figure 8) and ISO16028 (as shown in Figure 9), the structural forms and their pros and cons were investigated, analyzed and evaluated in detail, to provide a technical reference for final selection of ISO16028 quick action coupling. The key problem was analyzed and discussed of changing the ISO16028 from manual docking to automatic docking.

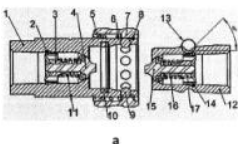

(a) disconnect

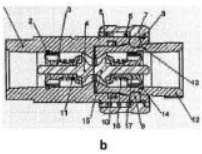

(b) connect

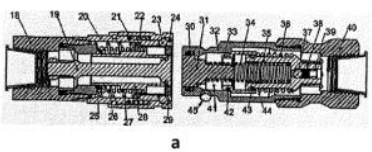

(a) disconnect

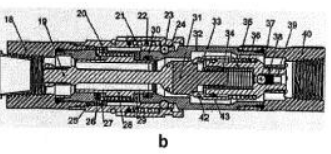

(b) connect

Figure 8. Structure drawing for ISO7241 quick action coupling

Figure 9. Structure drawing for ISO16028 quick action coupling

(3) Precise docking technology of quick action coupling. Inaccurate docking will seriously damage the quick action coupling and lead to failing connection and safety accident.

\subsection{Key technology in turning device for wrist}

The rotational DOF for wrist refers to the QHCD (with or without the attachments), which is driven by the turning device, rotating around the swaying device, in fact, it is realized by the relative rotation between the inner ring and the outer ring of the turning device. Due to the adoption of different inner/outer ring driving technology, the rotation of the $\mathrm{QHCD}$ of the main-ACW is driven by the inner ring of the turning device, but the rotation of the QHCD of the vice-ACW is driven by the outer ring of the turning device. The inner ring and the outer ring are supported by rolling elements, therefore, the one that integrates the inner ring, the outer ring and the rolling elements together is called a slewing bearing. A slewing bearing and a hydraulic motor are integrated together to form a turning device.

\subsubsection{Gear type turning device for main-ACW}

The supporting types of rolling elements of slewing bearing are mainly the single row 4-point contact ball type, the double row different diameter ball type, the single row cross roller type and the three row roller type, where the single row 4-point contact ball type in recent years developed rapidly to replace the double row different diameter ball type[25].

There are many domestic application researches on the slewing bearing. These application researches have gained extensive experience, especially, the single row 4-point contact ball type is the preferred type for the slewing bearing of small and medium size, but the three row roller type is the preferred type for the rotary support of large size[26], if it is an extra-large size rotary support, then its rolling elements are enlarged to the rolling wheels, such as trolley type conical rolling wheels, multi row rolling wheels and chain rolling wheels, and so on[27].

Because the gear transmission ratio is not large, it will cause too large radial size to the slewing bearing, but the main-ACW does not require compact structure, so the radial size of its slewing bearing is not strictly required, but just meeting the load requirement will be fine for the slewing bearing, therefore, the technology of gear driving slewing bearing with the single row 4-point contact ball type has been used in the turning device for the main-ACW as shown in Figure 10. The outer ring 
of the slewing bearing is fixedly connected with the swaying device, and the inner ring is actually an inner tooth big gear, which is fixedly connected with the QHCD and is driven by the outer small gear on the hydraulic motor.

\subsubsection{Worm type turning device for vice-ACW}

The gear pair has high efficiency, long life and high reliability, but when its transmission ratio increases, the dimensions of its space will swell correspondingly, so it is not suitable for the application in large transmission ratio conditions, but the worm pair is just applicable to these conditions. Because under the premise of the vice-ACW meeting the load requirements it should have a structure as compact as possible, a volume as small as possible, and a running as dexterous as possible (i.e., not too fast but also not too slow), so it can't use the gear type turning device of large radial size similar with the one for the main-ACW.

Based on the investigation, it has been found that HKS company in Germany uses the worm type turning device to achieve the goal of compact structure, small volume and dexterous running (it can reach up to a too fast speed of $8 \mathrm{r} / \mathrm{min}$ ). But the best domestic product actually can only reach an extremely slow speed of $1.5 \mathrm{r} / \mathrm{min}$ (corresponding to the flowrate of $30 \mathrm{~L} / \mathrm{min}$ for the hydraulic motor, but the HKS product can reach $8 \mathrm{r} / \mathrm{min}$ at the flowrate of $45 \mathrm{~L} / \mathrm{min}$ ). The inner ring of the slewing bearing of this kind of worm type turning device is fixedly connected with the swaying device, and the outer ring, which is actually a worm gear (with solid model of gear tooth profile, and its appearance is similar to gear) as shown in Figure 11, is fixedly connected with the QHCD, and is meshed with the
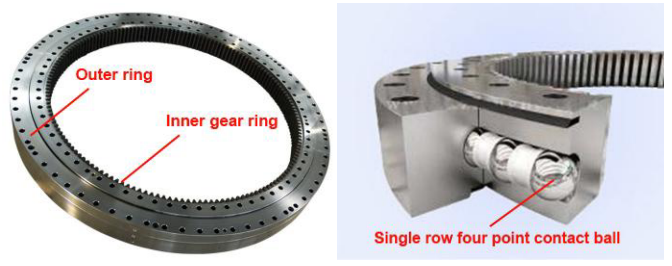

Figure 10. Gear driving slewing bearing with single row 4-point contact ball type

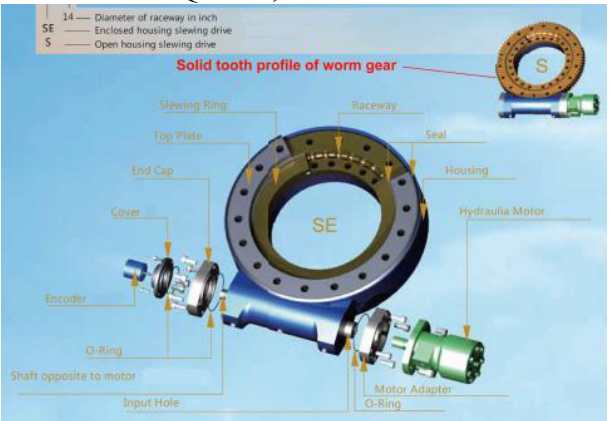

Figure 11. Worm type turning device product of domestic company in China

worm driven by the hydraulic motor. It still has some differences in details with the one of HKS company in Germany, which are mainly that, the outer ring is actually a shell and is fixedly connected with the swaying device, the inner ring is a worm gear (with empty model of gear tooth profile, and its appearance is similar to wheel) as shown in Figure 12, which is fixedly connected with the QHCD and is meshed with the worm driven by the hydraulic motor, i.e., the turning device is composed of a disassembled set of 4 including a shell, a worm gear, a worm and a hydraulic motor, and is 1 piece less than the domestic one, which is composed of a disassembled set of 5 including a shell, a worm gear, an inner ring, a worm and a hydraulic motor, therefore, the HKS turning device has a more compact structure. Therefore, both the speed $(1.5 \mathrm{r} / \mathrm{min}$ or $8 \mathrm{r} / \mathrm{min}$ ) and the structure (loose or compact) are the main gaps existing between the domestic and foreign products from which the proper turning device is intended to be selected for a large-scale rescue robot wrist.

\subsection{Key technology in swaying device for wrist}

The swing DOF for wrist refers to the swaying device together with the turning device and the QHCD (with or without the attachments), which is driven hydraulically, swinging relative to main/vice arm end, in fact, it is realized by the relative swinging between the swaying device and the upper coupling parts. Due to the adoption of different swaying realizing technology, their structures vary greatly. 


\subsubsection{4-bar linkage cylinder type swaying device for main-ACW}

The swing motion of the 4-bar linkage cylinder type swaying device is similar to the rotating motion of the hoist boom, which is changed from the linear motion of the piston of the hydraulic cylinder by a crane, and which longitudinally swings upward and downward, therefore, the hoist boom, the crane body and the hydraulic cylinder the three actually constitutes a 4-bar linkage mechanism[28] as shown in Figure 13, hereinto only can the length of the straight line segment, which is composed of the

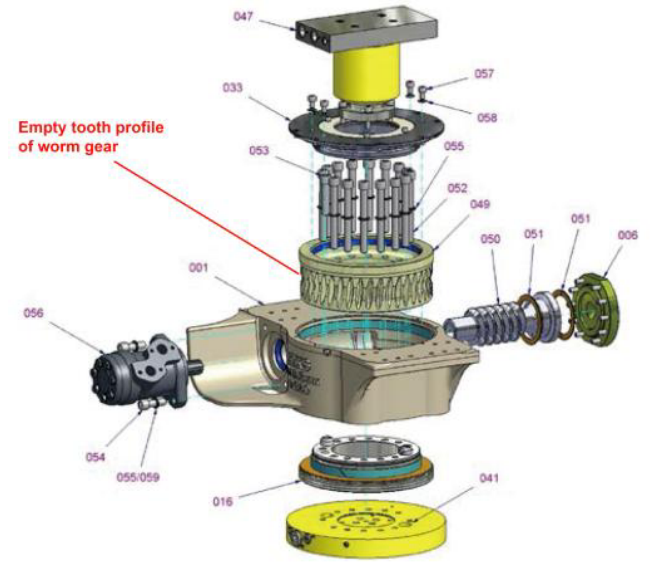

Figure 12. Worm type turning device product of HKS company in Germany
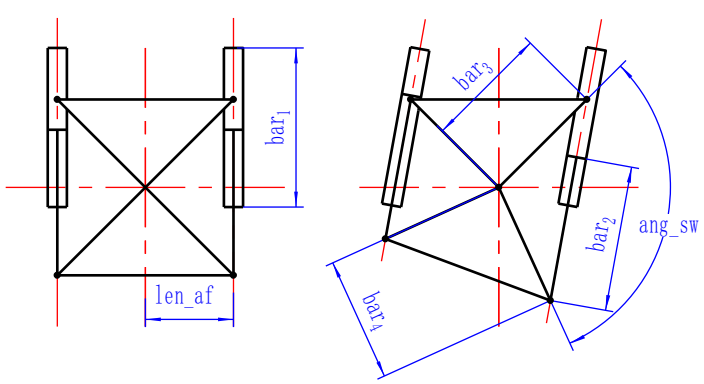

Figure 13. 4-bar linkage cylinder type mechanism

corresponding cylinder barrel bar ${ }_{1}$ and the piston $\operatorname{rod}_{\text {bar }}$ the two bars, be variable, and thus change the corresponding included angle ang sw of the triangle as shown in Figure 13, i.e., the longitudinal swing angle of the hoist boom, the swing motion of both the big arm and the small arm of the excavator is also realized by the same technology of 4-bar linkage cylinder. The technology of bilateral symmetric 4-bar linkage double cylinders used in the main-ACW of the large-scale rescue robot is shown in Figure 3. Due to the adoption of high pressure double acting single piston rod hydraulic cylinder, so a short swing arm of force (the distance between the hydraulic cylinder axis and the swing axis, i.e., the dimension len_af as shown in Figure 13) can generate a large swing moment. But the shortcoming of this kind of 4-bar linkage cylinder type swaying device is that the maximum swing angle (the dimension ang_sw as shown in Figure 13) is restricted by the limit of piston stroke, if the maximum swing angle is larger, the hydraulic cylinder length will be longer, and the overall dimensions will be bigger, as a result, the overall structure will be more loose rather than compact.

\subsubsection{Double spiral swing cylinder type swaying device for vice-ACW}

The 4-bar linkage cylinder technology is to indirectly change the linear reciprocating motion of piston into the swing motion of other bars with the aid of 4-bar linkage mechanism, the piston itself has no rotation movement, the existence of the 4-bar linkage mechanism makes this kind of device structure certainly to be loose, so it is not applicable in the vice-ACW which requires that the overall structure should be as compact as possible. The load bearing ability of the vane swing cylinder is not well, it is difficult for the working cavity seal, the internal leakage is large, the volumetric efficiency is low, and it is hard to increase the working pressure, so its usage is very limited, and it is usually only applicable to be used in such low pressure equipment as servo turret and so on. To deliver exactly the same movement and torque, the space occupied by the gear rack swing cylinder is larger than the vane swing cylinder, so the gear rack swing cylinder usage is much more restricted. The spiral swing cylinder can change the linear reciprocating motion of the piston of the hydraulic cylinder into a clockwise and anti-clockwise rotation of the 2 directions and output a swing motion and a swing moment[29]. Through two stage screw pair amplification effect, only need a short piston stroke can 
output a large swing angle, in addition, a double helix swing cylinder has a more compact structure and a larger output swing angle than a single spiral swing cylinder, thus it becomes the first choice for the vice-ACW as shown in Figure 14.

It began from around 1999, the domestic preliminary study on the spiral swing cylinder technology of this kind of product, manufactured by such foreign companies as Helac company in U.S.A.[30] and HKS company in Germany, has been made[31-34], until 2010 the research gradually increased, up to now it only has less than 10 years of time, and it is mainly theoretical and experimental research, including transmission efficiency, structure design and optimization[35], and a few researches also on robot applications[36-38].

HKS company in Germany can alone complete the 2 DOFs of the vice-ACW for the large-scale rescue robot, and the connecting dimensions between the turning device and the swaying device have good compatibility, therefore, there are a very high integration level and a very compact structure and almost no redundancy volume and weight between the 2 DOFs as shown in Figure 15. But currently there are no such similar domestic manufacturers, thereby needing two different professional manufacturers respectively to complete the 2 DOFs, the poor compatibility of the connecting dimensions between the 2 DOFs is inevitable, when the 2 DOFs are integrated together by the third party, the connecting transition flange has to be required to add additionally between the 2 DOFs, resulting in a lot of redundant volume and weight, together with the gap of the performance and the immature of the technology existing in the 2 DOFs, therefore, they can't be completely replaced by HKS company's products. In addition, because there are no mature products for selection for the actual engineering application of the double spiral swing cylinder on the robot, it often need to be developed separately by such as G.S. Luo et al.[36-38], but the accumulated experience during the period of less than 10 years is limited and there are not enough actual/simulated rescue combats for

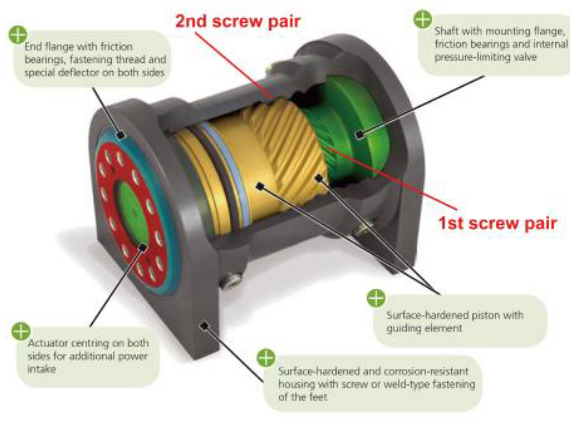

Figure 14. Two screw pairs of double spiral Figure 15. Two DOFs product of HKS company in

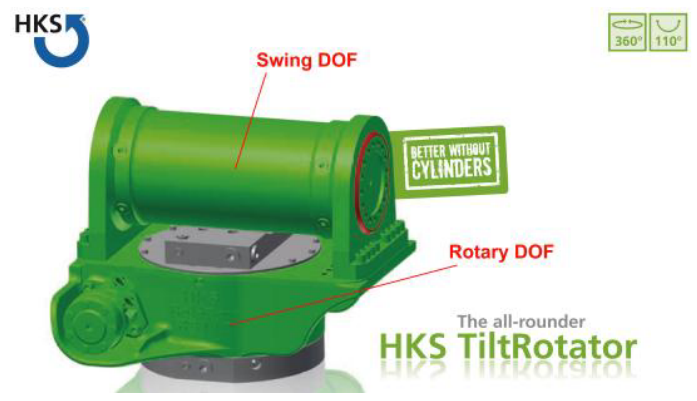

verifications, which lead to not dare to select for use rashly even if it has been developed out, therefore, this is the main gap existing between the domestic and foreign products from which the proper swaying device is intended to be selected for a large-scale rescue robot wrist.

\section{Conclusion}

(1) The full-AQHCD is the first bright spot in the vice-ACW, three key technologies involved should be tackled for clearing away obstacles of localization.

(2) Key technologies in the main/vice-ACW for the large-scale rescue robot have not the interchangeability, and they have the shortcomings caused by structural reasons themselves which cannot be overcome, at present, no better technologies at home and abroad can be an alternative.

(3) The 2 DOFs product of HKS is the second bright spot in the vice-ACW. If the "DPIDASLSRR" project is going to change prototypes into products in the short term, the suggestion is that the realization of the 2 DOFs for the vice-ACW should be still imported from HKS company in Germany.

(4) Knowing the existing gaps is not shameful unless ignoring them and rejecting to learn the 
world, therefore, this is the future work of the vice-ACW for "DPIDASLSRR".

\section{References}

1. OilQuick AB. OQ 65 suitable for machines from 14-22 t [EB/OL]. http://www.oilquick.com/oq-65. (2016-01-01)

2. HKS. Home [EB/OL]. https://www.hks-partner.com/en/home/. (2016-01-01)

3. HKS. TiltRotator $[\mathrm{EB} / \mathrm{OL}]$. https://www.hks-partner.com/en/products/construction-technology-series/tiltrotator/. (2016-01-01)

4. L. Chen. A rescue robot should be paid more attention to "Troops are kept a thousand days" than "To be used on one day"[N/OL]. Science and Technology Daily,2013-05-21. http://digitalpaper.stdaily.com/http_www.kjrb.com/kjrb/html/2013-05/21/content_204231.htm?di $\mathrm{v}=-1$. (2016-01-01)

5. W.M. Barden. Quick coupling device: US5581917[P]. (1996-12-10)

6. Y.B. Gao. The Optimization design on quick-coupler device of loader [D]. (Daqing: Northeast Petroleum University, 2013)

7. A.L. Vering, K.E. Lindenmuth, R.K. Oswald. Quick coupler: US7882898[P]. (2011-02-08)

8. d\&ri. Quick hitch guidance [J]. Demolition \& Recycling International. 12, 2:4-4 (Mar/Apr2010)

9. ce.UK semi-automatic quick hitches ban sought [J]. Construction Europe. 21, 8:7-7 (Oct2010)

10. X.S. Meng. Study on the standardization of the connection dimensions between the excavator and the quick change device [J]. CONSTRUCTION MACHINERY DIGEST, 03:43-45 (2013)

11. GEITH Inc. Quick coupler provides automatic, double-locking attachment system [J]. Pit \& Quarry. 107, 8:28-28 (Feb2015)

12. GEITH International Ltd. New couplers from Geith [J]. International Cranes \& Specialized Transport. 26, 5:48-48 (Jun2015)

13. P. McCormick, C. McCormick, L. McCormick, et al. A quick hitch coupler: WO2011051923[P]. (2011-05-05)

14. P. McCormick, C. McCormick, L. McCormick, et al. Quick hitch coupler: US2012210614[P]. (2012-08-23)

15. P. McCormick, C. McCormick, L. McCormick, et al. Quick hitch coupler: US8857081[P]. (2014-10-14)

16. T.C. Robl, T.R. Stefek. Quick coupler: US2013322954[P]. (2013-12-05)

17. T.C. Robl, T.R. Stefek. Quick coupler: US8869437[P]. (2014-10-28)

18. J. Parker, H.P. Gaines. Quick coupler: US2013160268[P]. (2013-06-27)

19. J. Parker, H.P. Gaines. Quick coupler: US2013160269[P]. (2013-06-27)

20. T. Friedrich. Quick coupler: US2014030005[P]. (2014-01-30)

21. T. Friedrich. Quick-coupler: US2014356059[P]. (2014-12-04)

22. T. Friedrich. Quick-coupler: US2014373401[P]. (2014-12-25)

23. R.(DE) Mieger, T.(DE) Zitterbart. Quick coupling: US2002157287[P]. (2002-10-31)

24. T.(DE) Zitterbart, R.(DE) Mieger. Quick coupling: US6813851[P]. (2004-11-9)

25. Y.Q. Wang, Q. Fang. Style-choosing calculation and designing of revolving support mechanism of hydraulic excavator [J]. Coal Mine Machinery, 27, 11:4-6 (2006)

26. J. Dai. Reasonable choice of rotatory bearings [J]. MECHANICAL AND ELECTRICAL EQUIPMENT, 05:85-87 (2006)

27. Y.M. Wang, Y.L. Wang, M.H. Tong. Enabling technologies for new rotary support device of ultra-large-scale rotary floating cranes [J]. CHINESE JOURNAL OF CONSTRUCTION MACHINERY, 7, 02:180-184 (2009)

28. Y. Xiang, N. Chen, Y.X. Hu, et al. Analysis and study of swing mechanism of boom type roadheader[J]. COLLIERY MECHANICAL \& ELECTRICAL TECHNOLOGY, 03:4-6+11 (2001)

29. G. Li. Typical application of swing hydraulic cylinder [J]. Metal Working(Cold), 21:56-57 (2013)

30. Helac Corporation. Home [EB/OL]. http://www.helac.com/. (2016-01-01) 
31. Y.P. Shi, L. Yang. Design of large swing angle spiral swing hydraulic cylinder [J]. Chinese Hydraulics \& Pneumatics, 06:5-7 (1999)

32. Y.P. Shi, L. Yang. Design of spiral swing cylinder with large swing angle [J]. MACHINE TOOL \& HYDRAULICS, 01:62-63 (2000)

33. J.G. Zhang. Design of spiral swing cylinder with large swing angle [J]. Journal of Lianyungang College of Chemical Technology, 13, 01:16-19 (2000)

34. Z.M. Jin. Dynamic and accurate matters -- HKS oscillating hydraulic cylinder [J]. Modern Components, 08:40-41 (2004)

35. S.G. Xie. Design and optimization of the structure parameters of the double helix rotating cylinder based on virtual prototype technology [D]. (Changsha: Central South University, 2010)

36. G.S. Luo. Research on subsea 7 function maser-slave manipulator and its nonlinear robust control [D]. (Hangzhou: Zhejiang University, 2013)

37. G.S. Luo, J.W. Chen, L.Y. Gu. An elbow of 7-DOF hydraulic manipulator based on double-screw-pair transmission [J]. ROBOT, 36, 01:36-42 (2014)

38. M.S. Lu. The structural design of underwater manipulator based on hydraulic spiral swing cylinder [D]. (Hangzhou: Hangzhou Dianzi University, 2015) 